\title{
Fronteiras Culturais: impactos e contatos na descoberta e colonização do Brasil
}

ARNO ALVAREZ KERN"

Resumo: O texto analisa como ocorreu na América atlântica, a partir da conquista e da colonização, um complexo processo de transformações culturais quando dos contatos entre a sociedade ibérica e os grupos indígenas americanos. A cultura da sociedade dominante ibérica conquistou as culturas das sociedades locais, além de receber importantes influências destas, em uma síntese cultural ibero-indígena. Os contatos culturais se relacionam à nova sociedade colonial americana, sensivelmente diferente daquelas que lhes tinha dado origem.

Abstract: This paper analyses how the complex process of cultural transformation in Atlantic America occurred after the Iberian conquest, colonization and contacts between the Iberian society and American Indian groups. The culture of the dominate Iberian society conquered the local Indian culture, but received important influences from it, leading to an Indian-Iberian cultural synthesis. Those cultural contacts are now related to the new American colonial society, very different from the original one.

Palavras-chave: Sociedade ibero-indígena. Síntese cultural ibero-indígena. Cultura material.

Key words: Indian-Iberian society. Indian-Iberian cultural synthesis. Material culture.

O presente texto foi apresentado no ciclo de conferências "Brasil 500 anos: descobertas e redescobertas", promovido pelo Programa de Pós-Graduação em História da PUCRS. Versões iniciais ou resumidas foram apresentadas na Reunião Científica da AHILA (Porto, Portugal, 1999), no 50 Congresso Internacional dos Americanistas (Varsóvia, Polônia, 2000) e na XX Reunião Anual da Sociedade Brasileira de Pesquisa Histórica (Rio de Janeiro, Brasil, 2000).

Arqueólogo e Historiador. Professor dos Cursos de Pós-Graduação em História da Faculdade de Filosofia e Ciências Humanas da Pontifícia Universidade Católica do Rio Grande do Sul, Porto Alegre, Brasil. 


\section{Introdução}

Um dos episódios da expansão ultramarina luso-espanhola foi a descoberta da América Meridional e sua conseqüente colonização, a partir do século XVI. Esse processo de ocupação do território deu origem a um processo extremamente complexo de relações entre as sociedades indígenas, que aqui se haviam instalado nos últimos dez mil anos, e os grupos populacionais ibéricos que aqui chegaram durante o período colonial, julgando-se as descobridoras deste Novo Mundo. Nenhuma dessas sociedades que aqui se estabeleceram, entretanto, são autóctones. Os grupos indígenas vieram da Ásia, provavelmente em migrações sucessivas, no decorrer da última glaciação. Foram pouco a pouco descobrindo, colonizando e ocupando o imenso território americano, e'procurando formas mais eficientes de adaptação às paleopaisagens frias e secas da época glacial. Ao longo dos milênios, terminaram por ocupar toda a América do Sul. Alguns grupos permaneceram nômades e caçadores-coletores-pescadores. Outros deram origem a sociedades muito complexas e diferenciadas, estabelecidas em aldeias no Amazonas ou mesmo em cidades nas montanhas dos Andes e no altiplano boliviano. Esses grupos nativos sulamericanos, no limiar da Idade Moderna, não poderiam ter idéia de que seus destinos históricos estavam relacionados com outros grupos provenientes de duas longínquas nações ibéricas, Portugal e Espanha.'

O processo de reconquista da Península Ibérica se encadeia historicamente com a conquista e colonização do Novo Mundo. Quando os portugueses e os espanhóis aqui se estabeleceram nos inícios do século XVI, encontraram paisagens diversificadas e sociedades indígenas muito diferentes umas das outras. Os contextos ambientais nos quais os grupos indígenas estavam instalados eram muito diversos, variando não apenas no que diz respeito ao relevo, mas igualmente quanto ao clima, à flora e à fauna. Nos litorais quentes e úmidos ou nas alturas frias do planalto brasileiro, nas imensas extensões das florestas tropicais amazônica e atlântica, ou nas vastas paisagens cobertas de gramíneas dos campos e dos pampas, esses ambientes distintos exigiam dos grupos

Esse estudo foi extensamente desenvolvido em KERN, Arno Alvarez. Antecedentes indigenas. Porto Alegre: Editora da Universidade (Série Síntese Riograndense, n ${ }^{0} 16-$ 17), 1994. 
indígenas adaptações culturais muito específicas. ${ }^{2}$ Nessas paisagens estavam instalados grupos nômades de caçadores-coletorespescadores, parcialidades étnicas formadas por aldeões horticultores semi-sedentários, alguns organizados quase militarmente com seus guerreiros, como é o caso dos Tupi-guarani. Todos esses grupos, direta ou indiretamente, entraram em contato entre si ou por intermédio de seus vizinhos. Realizaram trocas através de intercâmbios culturais, ou chocaram-se entre si em guerras de conquista e expansões colonizadoras, como é o caso da Tupinização do Brasil tropical e da Guaranização do Brasil subtropical e de áreas importantes no restante da região platina.

Entretanto, é a partir da colonização e do povoamento encetados pelos portugueses e pelos espanhóis, nos momentos posteriores à expansão ultramarina, que os grupos indígenas começaram a sofrer alterações sociais e culturais profundas, e muitas vezes traumáticas, como consequiência dos impactos e dos contatos decorrentes. ${ }^{3}$ No passado, nenhuma empresa de conquista fora de tal modo extensa nem uma exploração econômica realizada com tal intensidade, nas imensas paisagens desta América Indígena.

Desse complexo processo, que originou novas histórias de longa duração nas diversas paisagens culturais deste Brasil múltiplo, emergiu uma nova sociedade colonial ibero-indígena, a qual terminou sendo a base da organização de nossa atual América Latina.

Muitas das afirmações que constantemente são difundidas, principalmente em jornais e revistas, mas igualmente em muitos livros didáticos, relacionadas ao processo de descoberta e colonização da América, não passam muitas vezes de chavões e afirmações superficiais, interpretações subjetivas e carregadas de emoção, muitas vezes metáforas com muito pouco de conteúdo histórico. ${ }^{4}$ Assim, designam-se os protagonistas dessa história como

2 COUTO, Jorge. A construção do Brasil. Lisboa: Cosmos, 1995. Especialmente os capítulos 1: "As sociedades indígenas" (p. 39 e segs.), e 2: "A aculturação" (p. 309 e segs.).

3 KERN, Arno Alvarez. "Descoberta e colonização da América: impactos e contatos entre sociedades indígenas e européias". In: Anais (I Encontro de Cultura Ameríndia). Santo Ângelo: URI, v. 1, p. 9-14, 1992. Essa colonização foi também a responsável pela migração forçada de outros grupos, de origem africana, que aqui chegaram como escravos, mas que não serão mencionados neste estudo.

Não se trata de dedutivismo nem de indutivismo, mas das formas mais ingênuas de reducionismo. Um exemplo disso foram diversas publicações realizadas em reuniões científicas durante as comemorações da descoberta da América. Veja-se, como exemplo, o ensaio de IGLÉSIAS, Francisco. "Encontro de duas culturas: América e 
europeus e vencedores, de um lado, como indígenas e vencidos, de outro lado, esquecendo-se dos vencidos e vencedores dos conflitos existentes no seio das próprias sociedades européia e indígena. Afirmam igualmente terem os europeus aniquilado as culturas nativas e dizimado as populações indígenas. Enquanto isto, em toda a América, os grupos nativos e sua rica cultura ainda hoje são presença constante em alguns lugares, e uma herança cultural não negligenciável subsiste, mesmo em zonas onde são raros ou inexistentes seus descendentes. ${ }^{5}$ Essas generalizações são feitas de maneira muito simplista, mesmo que contenham parcelas de verdade. Em primeiro lugar, nenhuma análise maniqueísta dessas sociedades nos esclarece muito ou amplia o nosso conhecimento, pois o que se ganha em simplificação, é perdido em conteúdo histórico. Em segundo lugar, devemos dar mais ênfase às informações dos documentos da cultura material e da iconografia da época, até agora mal aproveitados ou simplesmente ignorados. Em terceiro lugar, devemos levar em conta não apenas as múltiplas fronteiras culturais já existentes antes mesmo da chegada dos grupos ibéricos, além de explicitar as novas áreas fronteiriças resultantes dos episódios da conquista e da colonização. É necessário também situar a expansão ultramarina e a colonização da América em seu contexto histórico e a partir de uma dupla perspectiva, européia de um lado e indígena de outro, sem ignorar as diferentes formas de contatos entre as diversas etnias em presença, bem como as historicidades específicas deles resultantes. Finalmente, como são complexos esses contextos, nos quais múltiplas variáveis devem ser levadas em conta e analisadas em suas inter-relações dialéticas, não podemos ignorar os recentes conhecimentos produzidos a partir de estudos da cultura material. Apenas poderemos reconstituir historicamente essa realidade passada se soubermos utilizar modelos de múltiplas variáveis e um raciocínio complexo, tentando compreender as múltiplas fronteiras culturais e as culturas nestas fronteiras.

Europa”. In: AZEVEDO, Francisca L. N. \& MONTEIRO, John M. (orgs.). Confronto de culturas: conquista, resistência e transformação. São Paulo: EDUSP, 1997, p. 23 e segs.

5 KERN, Arno Alvarez. Os Índios: no limiar da América Latina. In: KERN, Arno Alvarez et al. Rio Grande do Sul: continente múltiplo. Porto Alegre: Marprom/Riocel, 1993, p. 33-60. 


\section{A formação da sociedade ibero-indígena colonial}

Não podemos ignorar a complexidade do processo histórico que deu origem à sociedade americana colonial, a partir de seus segmentos indígena e europeu. Não nos basta afirmar simplesmente que houve miscigenação, quando as duas sociedades entraram em contato, como consequiência da expansão ultramarina ibérica. Essa nova sociedade apresenta uma série de elementos socioculturais específicos. Neste imenso continente sul-americano, as especificidades dos contatos e dos impactos nos permitem desvelar historicidades diferentes.

Numa primeira abordagem, somos obrigados a levar em consideração, que as paisagens onde se desenvolveram essas relações interétnicas foram muito diferenciadas, com relevos, climas, flora e faunas distintos. Com suas formas enérgicas de relevo, os picos, as montanhas e os vulcões dos Andes se antepõem às imensas planícies do Amazonas e dos Pampas, localizadas no lado atlântico. $\mathrm{O}$ clima equatorial quente e úmido do norte do continente sul-americano contrasta com os ventos frios, os gelos e as neves das alturas dos Andes ou das latitudes meridionais da Patagônia. As paisagens vegetais apresentam igualmente diferenças muito grandes, quando comparamos, por exemplo, os infindáveis tapetes de gramíneas dos Pampas e da Patagônia, com as densas florestas tropicais e subtropicais das vertentes atlânticas.

Os grupos indígenas estavam estabelecidos nesses diversos ambientes com padrões adaptativos diferenciados, a partir de tradições culturais estabelecidas desde muitos séculos. A base para a formação dessas sociedades nativas foram os primeiros grupos de caçadores, coletores e pescadores, que aqui se estabeleceram em plena glaciação. Entretanto, no decorrer do período pós-glacial, nos últimos 10.000 anos $^{6}$, esses grupos se transformaram de maneira extraordinária, diferenciando-se entre si, até os momentos que antecederam a descoberta da América.

Importantes processos de colonização e de integração cultural já haviam ocorrido anteriormente à chegada dos europeus. As margens do Oceano Atlântico foram o palco no qual se desenrolaram as extensas migrações colonizadoras dos grupos Tupi e Guarani, que terminaram ocupando áreas imensas, impondo sua cultura e sua língua. Mais recentemente, no litoral do Oceano Pacífico, os Incas se apoderaram militarmente de imensas áreas andinas.

O estudo sobre as paleopaisagens e as adaptações culturais dos grupos indígenas foi realizado em KERN, Arno A. (org.). Arqueologia pré-histórica do Rio Grande do Sul. Porto Alegre: Mercado Aberto, 1991. 
Assim, muito antes de se iniciar o processo histórico provocado pelo descobrimento da América pelos europeus, este continente já possuía uma história de longa duração, na qual as sociedades indígenas americanas desenvolveram profundas diferenças étnicas e culturais, após muitos milênios de processo histórico e desenvolvimento específico em cada um desses ambientes. Como exemplo, poderíamos destacar as sociedades andinas estabelecidas em suas cidades, os grupos de horticultores instalados em aldeias localizadas em meio às matas tropicais, e os caçadores nômades das paisagens abertas dos pampas, e que coexistiam lado a lado, quando as primeiras velas européias despontaram no horizonte do Atlântico. As sociedades ibéricas que invadiram e colonizaram esta América ainda indígena, ao longo do século XVI, estabeleceram formas diferenciadas de relações socioculturais com essas variadas populações indígenas. Umas foram escravizadas e dizimadas, outras foram cooptadas como aliadas ou cristianizadas. E, finalmente, muitas permaneceram simplesmente ignoradas em algumas áreas de refúgio, para só serem contactadas recentemente.

Quais as motivações que impulsionaram as caravelas e as naus, de velames desfraldados ao vento, e que os indígenas pensavam ser ilhas flutuantes? Por que esses colonizadores brancos chegavam tão longe dos litorais europeus, com suas terríveis armas de fogo, suas ambições de conquista de riquezas e de homens, seu espírito de cruzada, suas idéias de combater o paganismo e difundir o cristianismo à luz mesmo das fogueiras da inquisição? Visavam atingir objetivos tão diferenciados como a riqueza de Eldorado ou a salvação das almas indígenas "para a maior glória de Deus". Por outro lado, quais as motivações que levariam as sociedades indígenas a se unirem como aliadas de portugueses e espanhóis nas guerras contra outros grupos indígenas?

$\mathrm{Na}$ conquista da América, imediatamente atrás dos colonizadores, ou mesmo com eles, chegaram os missionários. Os que realizaram as suas atividades de cristianização do indígena pertenceram basicamente a quatro ordens religiosas. Foram principalmente os mercenários, os franciscanos, os carmelitas e, os últimos a chegar, os jesuítas. E foram exatamente estes últimos que oportunizaram uma das mais extraordinárias experiências históricas de gradual inserção dos indígenas Guarani na sociedade espanhola, através da experiência dos Trinta Povos das Missões Jesuíticas platinas. Milhares foram os europeus que aqui chegaram. Uns

Ver os estudos publicados em CUNHA, Manuela Carneiro da. História dos índios no Brasil. São Paulo: Companhia das Letras, 1992. 
eram conquistadores e missionários, outros mercadores e funcionários da corte. Todos, entretanto, eram os enviados ou dos reis ou dos papas, e em nome desses personagens históricos eram justificadas as suas ações. Todos pretendiam a conquista, seja do ouro e da prata, seja das almas dos índios. Alguns buscarão o Eldorado, dentro do espírito mercantilista da época. Outros pretenderão uma "conquista espiritual" bem de acordo com as idéias de cruzada contra os infiéis. Todos terminaram mudando significativamente a face deste novo continente. ${ }^{8}$

As relações interétnicas estabelecidas foram muito diversificadas, porque os diversos grupos indígenas tiveram reações muito diferenciadas em relação aos novos invasores. Na América Latina atual ainda vivem grandes contingentes de população indígena, filhos dos sobreviventes da conquista. Entretanto, alguns grupos fizeram uma resistência constante e terminaram sendo dizimados, como conseqüência do impacto das guerras de extermínio feitas pelos conquistadores, quase imbatíveis com seus cavalos e armas de fogo. Os indígenas igualmente colaboraram com o branco invasor, colocando a seu serviço a força de trabalho de seus braços, alguns de livre vontade, como nas missões, outros esmagados pela escravidão nas minas de prata ou nas lavouras de cana. Geraram igualmente uma nova população de mestiços, a partir das relações interétnicas entre os europeus e os nativos. A interação entre brancos e índios terminou dando origem a uma herança genética indígena não negligenciável em milhares de mestiços, muitos dos quais terminaram por ascender socialmente. Por outro lado, se os contatos interétnicos levaram à miscigenação, as doenças dos brancos e suas formas extremas de exploração do braço indígena levaram ao impacto mortal e à crise demográfica das populações nativas. Após um rápido decréscimo da população indígena, ao longo do século XVI, foi ao longo do período colonial e de maneira muito lenta que as populações indígenas puderam, pouco a pouco, tornar a crescer.

A conquista e o povoamento implicaram, portanto, em duas facetas aparentemente contrastantes. Por um lado, no etnocídio de centenas de grupos indígenas, aniquilados física e culturalmente. Por outro lado, deu origem a um lento, gradual e ininterrupto processo de agregação forçada ou integração parcial dirigida dos grupos indígenas. Nesse processo, as comunidades indígenas so-

* SILVA, Maria B. N. (coord.). Cultura portuguesa na Terra de Santa Cruz. Lisboa: Estampa, 1995. Ver especialmente os trabalhos publicados na Parte 1: "Portugueses e índios" (p. 25 e segs.). 
breviventes foram sendo cooptadas e inseridas nas instituições formais dos impérios coloniais espanhol e português, assim como nas da Igreja Católica Romana.

\section{A síntese cultural ibero-indígena}

Um novo e imenso mundo se abria frente aos novos colonizadores europeus, povoado por milhares de grupos indígenas, com costumes e padrões culturais absolutamente novos para esses cristãos. Saídos há pouco da Idade Média, alguns pensavam ter chegado no paraíso, enquanto que outros se debatiam em dúvidas religiosas, questionando se este continente inteiro, jamais citado na Bíblia, não seria a terra de Satã, e se seus habitantes não estariam todos ainda marcados pelo pecado original. Alguns padrões culturais foram descritos em relatos da época como sendo aterrorizantes e bárbaros. Dentre eles se deu ênfase aos sacrifícios humanos dos Astecas ou à antropofagia dos Tupi-guarani, fazendo tremer homens que, entretanto, achavam justos os atos de fé da Inquisição, e não se perturbavam ao assistir à queima em praça pública de "infiéis" judeus e muçulmanos. Esses comportamentos dos guerreiros tupi-guaranis e dos grupos luso-espanhóis estão diretamente relacionados às guerras de reconquista ibérica ou de conquista e colonização tupi-guaranis.

Portugueses e espanhóis herdaram muito dos padrões culturais indígenas, ao mesmo tempo em que iam impondo os seus costumes europeus. Os indígenas ocultaram dos europeus muitos de seus traços culturais, principalmente os relacionados com os ritos e os mitos, enquanto que exigiam dos brancos exemplares de sua tecnologia avançada, tais como as lâminas de machado de ferro. Somos, portanto, obrigados a levar em conta a complexidade social e cultural desses diversos tipos de contatos que se estabeleceram entre esses grupos de origens diversas. Muitos indígenas tiveram de aceitar de maneira autoritária os padrões de comportamento dos europeus. Por outro lado, temos que considerar que algumas das inovações técnicas trazidas da Europa pelos lusoespanhóis eram desejadas e exigidas por eles, como é o caso das armas de fogo e dos instrumentos em ferro. Apesar da exploração mercantilista e do combate aos paganismo indígena, a sociedade ibérica não deixou de agregar, também, inúmeros padrões culturais dos nativos, como se evidencia ainda hoje na maioria dos países americanos. 
Tanto a sociedade européia como a indígena eram, nessa época, curiosas sínteses culturais, entre o tradicional e o moderno. Por um lado, as sociedades indígenas mantinham inúmeros padrões socioculturais antigos, tradições muito arraigadas de épocas em que predominavam os caçadores-coletores-pescadores, com seus artefatos de pedra lascada e osso. Entretanto, muitas sociedades já haviam acrescentado a essa herança as inovações modernizadoras oriundas do processo de neolitização, dentre as quais a vida em aldeias, a cerâmica, a pedra polida e a domesticação de plantas e animais. Outros grupos, localizados na zona andina, acrescentaram a esse legado tradicional as inovações modernizadoras do estado, da realeza, da vida em cidades com seus templos, palácios e uma cultura muito sofisticada. Nesta América Indígena as sociedades mesclavam as tradições arcaicas com inovações modernizadoras, muito originais, em complexas resultantes socioculturais.

Os contatos entre a sociedade ibérica luso-espanhola e as sociedades indígenas deram origem, portanto, a um processo de múltiplas influências culturais, no qual os diversos grupos indígenas americanos tiveram importante contribuição a dar. A domesticação de plantas nativas nos evidencia como foi fundamental essa herança cultural, ainda hoje encontrada em maior ou menor grau nos hábitos dos europeus aqui instalados e, posteriormente, na Europa. A invenção e o cultivo artificial do milho talvez seja a mais interessante dessas contribuições. Acrescente-se a ela a mandioca doce (aipim), as abóboras, os feijões, o cacau, as pimentas, as batatas (doce e "inglesa") e o algodão, são exemplos dessa contribuição cultural, e ainda hoje fazem parte de nossa dieta alimentar. O abacaxi, a goiaba, o caju, o amendoim, o coco, o abacate, o butiá e o araçá são algumas das frutas que eram coletadas e que passaram igualmente para nossos cardápios. Apesar de não contar a América com muitos animais domesticáveis, o controle sobre o peru, domesticado na América do Norte, e alguns camelídios andinos, tais como a alpaca, a vicunha e a lhama, na América do Sul, nos mostram também a sua importante colaboração nesse setor. Por outro lado, os europeus que aqui chegavam e se instalavam, traziam igualmente complexas combinações de elementos socioculturais antigos e novos. Por um lado, podemos destacar as inovações modernizadoras geradas pela efervescência cultural dos séculos XVI e XVII. São exemplo disso: a imprensa e o plano urba-

COUTO, Jorge. A construção do Brasil. Lisboa: Cosmos, 1995, p. 309 e segs.; KERN, Arno Alvarez. "Os Índios: no limiar da América Latina". 
nístico em forma de grade e com a "plaza mayor" das novas cidades renascentistas; as linhas sinuosas, decorativas e teatrais da ornamentação barroca; e as inovações técnicas dos grandes descobrimentos, tais como os conhecimentos náuticos, a bússola e a técnica de construção de grandes embarcações. Ao lado dessas, podiam ser encontradas formas socioculturais muito tradicionais e arcaicas, oriundas do mundo greco-romano ou fruto da herança medieval. Dentre elas, um desenvolvido artesanato, especializado na metalurgia do ferro, na elaboração da cerâmica em torno de oleiro, no uso da roda e do arado. Foram os europeus que introduziram na América muitos animais domesticados, tais como o gado cavalar e vacum, as ovelhas e os galináceos. Trouxeram também legumes e verduras, tais como o repolho e a alface, e frutas como os limões e as laranjas, os pêssegos e as pêras. Além dessa complexa herança cultural, os europeus introduziram na América muitos outros elementos culturais que estavam recebendo a partir dos descobrimentos e dos contatos com outros povos, tais como o arroz, o café, a banana e a cana de açúcar, os quais tiveram crescente importância econômica.

Assim, as contribuições culturais aqui citadas como exemplo nos evidenciam as mútuas influências exercidas entre essas sociedades em presença. Os europeus que para aqui vieram não tiveram sucesso em recriar totalmente a Europa na América, mas terminaram adequando-se a uma série de circunstâncias ambientais e históricas, bem como tendo de fazer muitas concessões sociais e culturais. ${ }^{10}$ Do norte ao sul deste continente americano, cada vez que tomamos o nosso banho diário, deitamos em uma rede, comemos pratos feitos com milho e mandioca, preparamos um chimarrão ou fazemos um churrasco, estamos diante de padrões culturais desconhecidos na Europa dos descobrimentos e típicos da América Indígena. O chimarrão dos gaúchos do pampa é um exemplo extraordinário dessa síntese cultural. O próprio consumo da infusão, com a utilização do porongo e da erva-mate, são contribuições indígenas. A contribuição cultural européia é a bomba de metal que substituiu o canudo de taquara, com pequenos furos na extremidade inferior destinados a evitar a passagem do pó da erva-mate, que os indígenas haviam utilizado sempre.

10 KERN, Antecedentes indigenas. 


\section{Conclusões}

As generalizações teóricas esboçadas acima, de maneira sintética, não apenas nos sugerem algumas reflexões, mas igualmente indicam algumas direções de investigação a serem ainda desenvolvidas. É necessário, antes de tudo, que se tenha como objetivo encontrar respostas para as questões científicas relacionadas ao estudo das múltiplas fronteiras culturais e das múltiplas culturas situadas nestas margens fronteiriças. As pesquisas atualmente em curso deverão também responder à imperiosa necessidade de redefinições dos processos históricos regionais que estão diretamente implicados com esses espaços fronteiriços. Readequar a utilização dos conceitos relacionados à noção de fronteira, seria outro objetivo que deveríamos igualmente buscar. E, finalmente, tornase necessário não ignorar as interfaces e os debates interculturais que nesses espaços fronteiriços se estabelecem, dando origem às sínteses culturais.

No atual estágio das investigações, como vimos sinteticamente, fronteiras culturais e ambientais separaram grupos indígenas diversificados e muitas vezes antagônicos, ao longo da história indígena da América. Após a conquista européia, e durante muito tempo, na América Indígena, que pouco a pouco se transformava em América Latina, coexistiram essas sociedades diversificadas. Por um lado, as complexidades da sociedade européia que emergia da Idade Média e que estava ainda dando origem ao Mundo Moderno. De outro lado, os grupos indígenas que emergiam dos tempos pré-históricos como caçadores nômades ou como aldeões horticultores, penetravam no seio desses impérios coloniais em pleno mercantilismo e barroco. Cada grupo parece encontrar-se em um momento diferente do tempo, caracterizando muito bem a problemática que os historiadores denominam de "a contemporaneidade do não contemporâneo".

Dessa maneira, ocorreu na América um complexo processo de transculturação, ou seja, de transformações culturais que ocorreram quando dos contatos entre a sociedade ibérica e os grupos indígenas americanos. Como vimos, um processo de interações socioculturais ocorreu entre as diversas sociedades em presença, cada uma em sua situação ambiental específica e com certas características de organização sociocultural singulares. Por meio dessas relações, a cultura da sociedade dominante ibérica, pouco a pouco, foi se amoldando e se impondo às culturas das sociedades dominadas, além de receber influências delas. Os contatos culturais permanentes deram origem a formas diferentes de alterações dos 
padrões tradicionais indígenas. A assimilação dos instrumentos de ferro, do torno e do forno de oleiro, das técnicas de construção arquitetônica européia, da domesticação de animais através do pastoreio, dos valores do cristianismo, dentre outros traços culturais, provocaram mudanças estruturais muito importantes. Os indígenas americanos deixaram de ser caçadores nômades ou horticultores da floresta subtropical, sem que por isso tenham se transformado em espanhóis ou portugueses. Estes últimos, por sua vez, terminaram dando origem a uma nova sociedade colonial americana, sensivelmente diferente daquela que lhes tinha dado origem. Essas especificidades históricas somente puderam ser perfeitamente compreendidas pelos portugueses e espanhóis da Península Ibérica, quando a América ibero-indígena decidiu realizar a sua independência política, rompendo com muitos dos laços de dependência em relação às metrópoles e decidindo seguir um caminho autônomo. 